\title{
Predictors of health anxiety during pregnancy
}

\author{
Julie Prescott ${ }^{1}$, Lynn Mackie $^{2}$, Amy Leigh Rathbone ${ }^{3}$ \\ ${ }^{1}$ School of Education and Psychology, University of Bolton, Bolton, United Kingdom; ${ }^{2}$ Educational Psychology Service, Bolton Metropolitan \\ Borough Council, Bolton, United Kingdom; ${ }^{3}$ School of Education and Psychology, University of Bolton, Bolton, United Kingdom \\ Contributions: (I) Conception and design: J Prescott, L Mackie; (II) Administrative support: None; (III) Provision of study materials or patients: J \\ Prescott, L Mackie; (IV) Collection and assembly of data: J Prescott, L Mackie; (V) Data analysis and interpretation: All authors; (VI) Manuscript \\ writing: All authors; (VII) Final approval of manuscript: All authors. \\ Correspondence to: Julie Prescott, PhD. School of Education and Psychology, University of Bolton, Bolton, United Kingdom. Email: j.prescott@bolton.ac.uk.
}

Background: The internet has become a quick, easy and accessible source for health-related information. Women are more likely to search for health information online and this likelihood increases further during pregnancy. Searching online for health-related information can have both positive and negative impacts upon levels of health anxiety during pregnancy. This research initially explored how health impacts heath anxiety during pregnancy. Secondly, the sources of offline support that predict health anxiety and thirdly, how online health seeking behaviour predicts health anxiety.

Methods: The sample consisted of 159 pregnant women who completed an online questionnaire to investigate significant predictors of health anxiety during pregnancy.

Results: Multiple regression analyses showed health anxiety increased during pregnancy when medical complications had been experienced in a previous pregnancy and if under medical treatment for a nonpregnancy related condition. Interestingly, health anxiety was not affected by medical complications in the current pregnancy. Knowing when you have had enough information and repeating searches were significant predictors of levels of health anxiety, whereas using the same or different sources was not.

Conclusions: For many the internet is a convenient platform for information however the information is not always accurate, reliable or helpful. Relevant health care professionals should continue to sign-post pregnant women to validated health information websites with the aim to reassure women during pregnancy. Further research in this area would benefit from exploring how women use the internet when pregnant and devising guidelines which can be followed and recommended when doing so.

Keywords: Pregnancy; anxiety; online; support; health

Received: 04 April 2018; Accepted: 23 April 2018; Published: 29 May 2018.

doi: $10.21037 /$ mhealth.2018.04.04

View this article at: http://dx.doi.org/10.21037/mhealth.2018.04.04

\section{Introduction}

Although the internet cannot be deemed a principal proxy of conventional care, it has become a fundamental alternate for those who face obstacles when attempting to access health care (1-3). Research has found that around $80 \%$ of internet users seek health information online $(2,4)$ for reasons such as convenience, anonymity, specialized advice and social support when feeling stressed or worried $(5,6)$. Women are more likely to search for health information online (7) and studies suggest that searches for health information increase during pregnancy (6). Indeed, research has found that women, as parents, are amongst the highest information-seekers who use the internet to confirm beliefs or get a "second opinion" (8). Women also use the internet to seek information regarding pregnancy and childbirth in particular, as pregnancy tends to trigger anxieties and worries, not usually considered $(9,10)$. Previous research suggests that health anxiety is not elevated during pregnancy, although health anxiety is higher for those women who have experienced complications during pregnancy (8). 
Research investigating the views of midwives highlights the concerns midwives have around the accuracy of the information pregnant women find through searching online for health-related information $(10,11)$. Information found online tends to supplement offline sources $(6,10)$, enabling patients to be more informed $(10,12)$ which allows women to feel a sense of control (13) and confidence in their decision-making (11). Reassurance is often sought online and this is especially pertinent for first time mothers $(6,9)$ with reassurance of foetal development the most cited online search topic of interest for pregnant women (14).

Due to the increase in the use of the internet for health information, concern has developed around how the internet can impact on health anxiety (illness anxiety disorder and somatic symptom disorder) and increase worry. This concern has led to the development of the term Cyberchondria. Cyberchondria has been defined as 'the unfounded escalation of concerns about common symptomatology, based on the review of search results and literature on the web' (15). However, definitions of, and research into, cyberchondria are based on an adaption of hypochondria as defined by the DSM-IV (16). Searching for health information online has been found to increase health anxiety. Research has found that those with high health anxiety searched online for information more frequently, spent longer searching and found the searches more worrying than those with low or no health anxiety (17). Frequent online health seekers have also been found to make more medical appointments, whilst for those with little to no health anxiety, findings posit that searching online decreased the number of visits they made to medical professionals (18). However, further exploration of the issue is needed to determine whether online health information seeking results in an increase in health care utilization, either on or offline. In a study of 104 Dutch participants (19) health anxious people were found to experience more negative consequences from searching for health information online. Participants with health anxiety were more likely to search for information online, more likely to post health-related questions on forums and were thereby actively engaged more in health-seeking behaviour online. Similarly, Lagoe and Atkin (20) found that health-anxious people are more likely to use online forums. In their study Lagoe and Atkin found the more efficacious internet users tended to corroborate information via more than one online source or site. Those with more perceived experience of the internet felt more confident in their ability to access information online and were therefore more inclined to search for information online.

As previously highlighted, searching for health information online whilst pregnant has many positive aspects $(6,10-12)$. Women can become more active in their own health care, increase health literacy and find reassurance. However, not all health information on the internet is validated. Women could find their self being inundated with false health information based on other people's beliefs or personal opinions and worse case scenarios (6). The vast amount of information and personal stories available which are easily accessible online suggest women must negotiate what information they take on board and how they react to the negative, personal experiences of other Mothers, due to numerous risks involved in pregnancy and childbirth $(6,13)$. Also, if women are searching multiple sources for answers to their health-related questions and multiple varying answers are being returned, women can become conflicted when deciding which information source to deem legitimate. This can be a causal factor for searching excessively. Due to this, there is the risk of increased anxiety levels and the onset of health anxiety can be instigated.

One such form of health anxiety, experienced by many women, is pregnancy-specific anxiety (21). It has been termed as such as levels of anxiety tend to be mild to moderate, if not non-existent prior to pregnancy. During pregnancy women experience numerous, unfamiliar, bodily alterations which can be anxiety provoking. Women with pregnancy specific anxiety pertaining to health, tend to display one of two types of behaviour. Women may become avoidant of healthcare or triggers of any kind and situations which could perceivably worsen the condition. Others may seek health information constantly and become obsessed with tests, general practitioner appointments or become enthralled with using the internet to research illness (22). Previous research has found that individuals with high levels of health anxiety have an attentional bias towards illness related information (23).

There are many reasons that pregnant women, suffering with pregnancy-specific anxiety choose online platforms to seek health-related information. For instance, previous research has reported that, on average, one in five clinical pregnancies is not viable due to miscarriage within the first trimester $(24,25)$. In consideration of this, the internet can be used by pregnant women to gain advice in regards to the best nutrition, exercises and precautions to take, weeks prior to actually being admitted under prenatal care. Being an informed patient when pregnant, can encourage women to further explore, at their own pace, health information 
which they are given prior to, during or post antenatal appointment $(6,13)$.

\section{Rationale and aims}

Since women utilize the internet for health information more so than men, and pregnancy and childbirth can be particularly worrying times for women, it was deemed important to consider how women use the internet during pregnancy for pregnancy related information. This research sought to understand the following three predictors of health anxiety during pregnancy. Firstly, how health impacts heath anxiety during pregnancy. Secondly, the sources of offline support that predicts health anxiety and thirdly, how online health seeking behaviour predicts health anxiety.

It was predicted that complications either associated to pregnancy or not would increase the likely hood of health anxiety during pregnancy especially if there were complications in a previous pregnancy or indeed the current pregnancy. It is suggested that levels of health anxiety can be managed and maintained if woman have adequate offline support; such as access to relevant medical health professionals and personal relationships. It was also hypothesised that repeating searches for health information and using different sources would be significant predictors of health anxiety during pregnancy.

\section{Method}

The larger study from which this paper is drawn took a mixed-methods approach, using both qualitative semistructured interviews with pregnant women and an online questionnaire for currently pregnant women and new parents, both male and female, in order to understand their online health information-seeking behaviour. The interviews and questionnaire elements of the study ran simultaneously in order for a larger, more diverse data set from which to derive results. The findings from the interviews are presented elsewhere (6). The aim of this paper is to discuss the findings from the currently pregnant questionnaire and investigate predictors of health anxiety during pregnancy. A total of 159 pregnant women completed the Pregnancy Questionnaire.

\section{Ethical and research approvals}

Approval for the study was given by University of Bolton Research Ethics Committee in October 2015, United
Kingdom.

\section{Materials}

The online Pregnancy Questionnaire was created using Google Forms. The questionnaire was inclusive of the Short Health Anxiety Inventory (26) which consists of 14 items. The questionnaire assesses health anxiety, feared consequences, health worry and awareness of body. The questions have multiple choices and the participant is asked to select the one they deemed most relevant to themselves. For example; (I) I do not worry about my health;(II) I occasionally worry about my health; (III) I spend much of my time worrying about my health; (IV) I spend most of my time worrying about my health. The health anxiety scores ranged from the lowest 5 to 29 . Since there is no standardized cut off score for the short version of the health anxiety inventory, the authors felt, based on previous research using the HAI short version (27), that a score below 10 equated to a low health anxiety, between 11 and 16; moderate health anxiety and a score above 18; high health anxiety. A decision informed by previous cut off points used for this scale.

The questionnaire also consisted of questions that explored how pregnant women utilise the internet when health information searching, e.g., do you tend to use the same or different sources when you repeat a search? Do you tend to know when you have had enough information? What forms of online and offline support they have and what positive (convenience of online health information searching) and negative (the increase of stress, anxiety and worry) consequences they experience from online health information searching.

\section{Recruitment procedure}

A page was created on Facebook to advertise the research and to contact local pregnancy groups, with links to the questionnaire. Additional posts on Facebook advertised face to face and telephone interviews. A Twitter account was also created to post links to the questionnaire and to contact recognised organisations to share the links to the research. All social media accounts created were associated with BIH Psychology. A website was designed, 'A Healthy Search', informing potential participants about the research and what they could do to take part. Links to the website were consistently posted on Facebook and Twitter, and included in a mailshot sent out to pregnancy and new 
parent organisations. Organisations who responded to the mailshot to engage with the research were NCT (National Childcare Trust), BabyCentre, Anatomy Manchester, Baby Ultrasound Clinic, Life Designs and More, Totally Holistic Health, Mamafit, Misfit Mamas, Wellbeing of Women, St Brendan's Nursery, Go Create 'Messy Play', Funtastic, John Krantz Psychological Research, Embrace Birthing.

Anatomy Manchester, Baby Ultrasound Clinic, Go Create 'Messy Play', Funtastic and Embrace Birthing requested hard copies of the questionnaire for their clients to complete. All hard copies were sent out to each of the organisations with return envelopes and flyers advertising the research. A public listing of the research was requested to John Krantz Psychological Research. The listing which shared the title of the research and a link to the website ran for 7 days. The research was included in newsletters at St Brendan's Nursery and Misfit Mamas. Misfit Mamas, along with Life Designs and More, Mamafit and Wellbeing of Women, all shared questionnaire links on Twitter. Totally Holistic Health shared links to the questionnaire in their own mailshot to clients. Links to the website and questionnaire were posted in forums on Netmums, BabyCentre, No More Panic, Emma's Diary, Pregnancy Forum, The Bump and What to Expect. Interviews were also advertised in forums. NCT, the UK's largest childcare organisation, created posts on Facebook and Twitter. The posts, displayed links to the questionnaire and the website and this was shared with NCT branches all over the UK. NCT branches also requested paper questionnaires and flyers advertising the research.

\section{Data analysis}

The data was analysed using IBM SPSS software version 21 . Data was tested for normality and then regression analyses were used to explore significant predictors of health anxiety in pregnant women.

\section{Results}

Of the 159 pregnant women that completed the questionnaire the majority (84\%) were aged $26-40$, $14 \%$ were aged $16-25$, and $2 \%$ were aged 41 and older. Demonstrating an almost equal distribution, $44 \%$ of women were primipara and $56 \%$ were multipara. $15 \%$ of the women were in their first trimester, $38 \%$ in their second trimester and almost half of participants (47\%) were in their third trimester.

\section{Regression 1: bealth factors}

An initial multiple regression analysis was run to explore whether; 'Have you been under medical care or supervision for a temporary or chronic health condition not related to your pregnancy in the last year?', 'Have you experienced any medical complications in a previous pregnancy?' And 'Have you experienced any medical complications in this pregnancy?' were significant predictors of health anxiety. Analysis summary shows that the model account for $10.9 \%$ of the variance and is significant $\mathrm{F}(3,155)=7.471, \mathrm{P}=0.000$, $\mathrm{R}^{2}=0.126, \mathrm{R}^{2}$ adjusted $=0.109$. Alone, 'Have you experienced any medical complications in this pregnancy?' was not a significant predictor of health anxiety $(\mathrm{P}=0.414)$ (Table 1).

\section{Regression 2: sources of offline support}

A second multiple regression was then used to explore data. Results show that in model 1 , 'Have you experienced any medical complications in this pregnancy?', as a sole predictor of health anxiety is not significant. However, in model 2, the use of offline sources were explored; 'Have you experienced any medical complications in this pregnancy?', 'Offline sources-midwife', 'Offline sourcespregnant friends/family' and 'Offline sources-doctor.' Model 2 was significant and explained $4.4 \%$ of the variance $\mathrm{F}(4,154)=5.777, \mathrm{P}=0.026, \mathrm{R}^{2}=0.069, \mathrm{R}^{2}$ adjusted $=0.044$. Within this model, the predictor, 'Have you experienced any medical complications in this pregnancy?' was only just significant $(\mathrm{P}=0.048)$; 'Offline sources—pregnant friends/ family’ was significant $(\mathrm{P}=0.014)$. However, Doctor and midwife were not (Table 2).

\section{Regression 3: online bealth information seeking behaviour}

A hierarchical multiple regression was then used to explore the data. Results show that in model 1, 'Do you tend to know when you have enough information?', as the only predictor of health anxiety explains $4 \%$ of the variance and is significant $\mathrm{F}(1,157)=7.629, \mathrm{P}=0.006, \mathrm{R}^{2}=0.046$, $\mathrm{R}^{2}$ adjusted $=0.40$.

Based on previous findings (6) it was proposed that the amount of information online, as well as the ability to repeat searches and repeat through different online sources would contribute to health anxiety during pregnancy.

In model 2, 'Do you ever repeat a search for information on a concern?' and 'Do you tend to use the same or different sources when you repeat a search?' were added. 
Table 1 Coefficients regression 1: health factors

\begin{tabular}{|c|c|c|c|c|c|}
\hline Model & \multicolumn{2}{|c|}{ Unstandardized coefficients } & $\begin{array}{c}\text { Standardized coefficients } \\
\text { Beta }\end{array}$ & $\mathrm{t}$ & Sig. \\
\hline \multicolumn{6}{|l|}{ Model 1} \\
\hline (Constant) & 37.468 & 2.875 & - & 13.030 & 0.000 \\
\hline $\begin{array}{l}\text { Have you been under medical care or supervision for } \\
\text { a temporary or chronic health condition not-related to } \\
\text { your pregnancy in the last year? }\end{array}$ & -3.806 & 1.119 & -0.256 & -3.401 & 0.001 \\
\hline $\begin{array}{l}\text { Have you experienced any medical complications in a } \\
\text { previous pregnancy? }\end{array}$ & -2.696 & 1.033 & -0.205 & -2.610 & 0.010 \\
\hline $\begin{array}{l}\text { Have you experienced any medical complications in } \\
\text { this pregnancy? }\end{array}$ & -0.853 & 1.041 & -0.064 & -0.820 & 0.414 \\
\hline
\end{tabular}

Dependent variable: HA-Main Score.

Table 2 Coefficients regression 2: sources of offline support

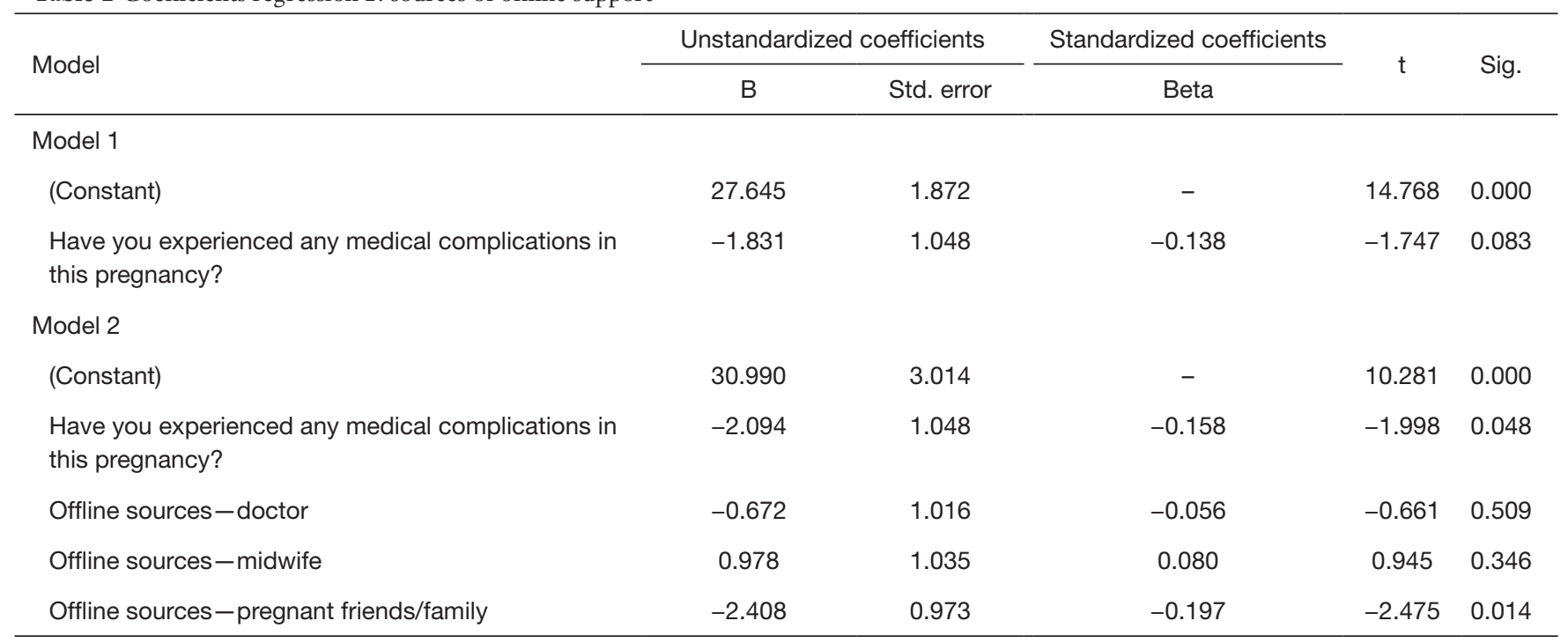

Dependent variable: HA-Main Score.

It was found that significantly more variance $(10.8 \%)$ was explained in model $2 \mathrm{~F}(3,155)=5.564, \mathrm{P}=0.000, \mathrm{R}^{2}=0.125$, $\mathrm{R}^{2}$ adjusted $=0.108$ (Table 3$)$.

\section{Discussion}

\section{Health factors}

The results from this study evidence that predictors of health anxiety during pregnancy include the health factors of medical complications experienced in a previous pregnancy or indeed if they are under medical treatment for a non-pregnancy related condition. It is perhaps understandable that women with previous complications, both pregnancy and non-pregnancy related, may have an increase in health anxiety and supports previous findings (8). However what is surprising is that health anxiety is not affected by medical complications in a current pregnancy. Although previous findings have found that health anxiety is not elevated during pregnancy, the findings that health anxiety is not increased with complications during the current pregnancy but does when the complications occurred in a previous pregnancy does raise some interesting questions. 
Table 3 Coefficients regression 3: online health information seeking behaviour

\begin{tabular}{|c|c|c|c|c|c|}
\hline Model & \multicolumn{2}{|c|}{ Unstandardized coefficients } & $\frac{\text { Standardized coefficients }}{\text { Beta }}$ & $\mathrm{t}$ & Sig. \\
\hline \multicolumn{6}{|l|}{ Model 1} \\
\hline (Constant) & 20.488 & 1.516 & - & 13.518 & 0.000 \\
\hline Do you tend to know when you have enough information? & 3.429 & 1.241 & 0.215 & 2.762 & 0.006 \\
\hline (Constant) & 24.221 & 2.887 & - & 8.389 & 0.000 \\
\hline Do you tend to know when you have enough information? & 2.987 & 1.216 & 0.188 & 2.456 & 0.015 \\
\hline Do you ever repeat a search for information on a concern? & -3.108 & 0.916 & -0.263 & -3.394 & 0.001 \\
\hline $\begin{array}{l}\text { Do you tend to use the same or different source when you } \\
\text { repeat a search? }\end{array}$ & 0.790 & 0.947 & 0.064 & 0.835 & 0.4205 \\
\hline
\end{tabular}

Dependent variable: HA-Main Score.

\section{Sources of offline support}

Further analysis of this topic showed that current pregnancy complications is a significant predictor of health anxiety when considered alongside types of offline support. Interestingly, doctors and midwives did not affect a pregnant woman's levels of health anxiety, whereas other pregnant family members and friends did. Since pregnancy is often viewed as worrying times for women $(9,10)$, it might be expected this worry would increase due to complications. However, if a pregnant woman is in receipt of offline support from others who are also pregnant, this perhaps provides them a particular level of reassurance. This could be due to the fact that their concerns can be voiced to and rationalised by another. This could also explain why current pregnancy complications are only slightly significant. Having this particular bond with family and friends could keep levels of health anxiety at a homeostasis, essentially deterring the need for the woman to search online excessively for health information. Conversely, perhaps information sought online is reassuring for women and therefore has no impact on health-related anxiety. Indeed reassurance is often sought online and this is especially pertinent for first time mothers $(6,9)$ with reassurance of fetal development the most cited online search topic of interest for pregnant women (14).

\section{Online bealth information seeking behaviour}

The benefits of accessing health information online include accessibility, convenience, anonymity and social support $(5,6)$. Individuals with high health anxiety search online for information more frequently, spend longer searching and find searches more worrying than those with low or no health anxiety (27). Indeed, savvy internet users acknowledge the expectation of worse case scenarios when searching for information online (6).

Knowing when you have enough information and repeating searches for a concern predicted health anxiety, whereas using the same or a different source did not. Therefore the wealth of information online and having the ability (or not) to know when you have read enough information predicts health anxiety of pregnant women. There is a possibility that this is due to an overwhelming amount of information. This could lead to further and repeated health information searches. As expected repeating searches also affects health anxiety during pregnancy.

The frequency of "Googling" symptoms increases levels of health anxiety. The phenomenon of "Googling" symptoms and ailments to gain an online self-diagnosis is not an accurate practise. Not all health information online is validated by health care professionals and several symptoms can be misinterpreted and lead to selfmisdiagnosis. Whilst searching online can return health information from innumerable sources; including from professional's sources such as the NHS, they also return personal accounts through blogs and forums which often include the worst case scenarios one might not otherwise encounter, essentially triggering health anxiety (6).

Pregnancy-specific health anxiety is a problematic occurrence that can affect the physical and psychological 
well-being of both the mother and child (21). It is imperative that concerns and worries related to the circumstances of pregnancy are relieved as much as possible to make pregnancy as comfortable as possible. It is suggested that pregnant women would benefit from further psycho-education on, not only health anxiety itself, but how to best utilise the internet for health information searching. Interestingly, Lagoe and Atkin (20) found the more efficacious internet users tended to corroborate information via more than one online source or site, often online forums. Suggesting a level of skilful surfing is required when searching for information online.

Regardless of what positive or negative effects searching online for health information can have on pregnant women's level of health anxiety, the internet will remain a source of data acquisition. Whilst this method of data acquisition should never be used as an alternative to health care delivered by trained professionals, there are several things which can be done to ensure that online health searching does not exacerbate health anxiety. General practitioners, midwives, health visitors and other relevant health care professionals should continue to sign post pregnant women to validated health information websites with the aim to reassure women during pregnancy.

\section{Limitations}

The study has a number of limitations, namely the relatively small online sample of pregnant women based in the UK. A larger sample would be more representative of this demographic. There was also a higher proportion of women in their third trimester. Women in the first and second trimesters may experience different levels of anxiety and a larger sample of women within these two trimester periods would have added to the analysis and the exploration of women's health anxiety during the different trimesters. Indeed the first trimester is perhaps the most worrying trimester for women since it is the time when miscarriage is most common (24).

\section{Further research}

It is salient that pregnant women who may experience pregnancy-specific anxiety or health anxiety are fully equipped with the skills to search for health information in a beneficial way. Further research in this area would benefit from further exploring how women use the internet when pregnant and devising guidelines which can be followed and recommended when doing so. The study highlights a number of issues significant to health anxiety during pregnancy, providing a platform for further work in the area of developing how to encourage people, in particular pregnant women, to skilfully surf whist searching for health information online.

\section{Acknowledgements}

None.

\section{Footnote}

Conflicts of Interest: The authors have no conflicts of interest to declare.

Ethical Statement: Approval for the study was given by University of Bolton Research Ethics Committee in October 2015, United Kingdom.

\section{References}

1. Fox S. Americans living with disability and their technology profile. Pew Research Center's Internet \& American Life Project. Available online: http://www. pewinternet.org/2011/01/21/americans-living-withdisability-and-their-technology-profile/

2. Fox S, Duggan M. Health Online 2013. Report by Pew Research Center Washington, DC; Available online: http://pewinternet.org/reports/2013/health-online.aspx

3. Sillence E, Briggs P, Harris PR., et al. How do patients evaluate and make use of online health information? Soc Sci Med 2007;64:1853-62.

4. Madden M, Rainie L. America's Online Pursuits: The Changing Picture of Who's Online and What They Do. Pew Internet \& American Life Project 2003. Available online: http://www.pewinternet.org/2003/12/22/americasonline-pursuits/

5. White M, Dorman SM. Receiving social support online: implications for health education. Health Educ Res 2001;16:693-707.

6. Prescott J, Mackie L. 'You sort of go down a rabbit hole... You're just going to keep on searching'. A qualitative study of searching online for pregnancy relates information during pregnancy. J Med Internet Res 2017;19:e194.

7. Hallyburton A, Evarts LA. Gender and online health information seeking: A five survey meta-analysis. J Consum Health Internet 2014;18:128-42. 
8. Kowalyk KM, Hadjistavropoulos HD, Jones SL. What impact does pregnancy have on anxiety about health? J Psychosom Obstet Gynaecol 2009;30:223-30.

9. Fox S. Health Topics 2011. Report by Pew Research Center Washington, DC; Available online: http://www. pewinternet.org/2011/05/12/health-topics/

10. Lagan BM, Sinclair M, Kernohan WG. A web-based survey of midwives' perceptions of women using the internet in pregnancy: a global phenomenon. Midwifery 2011;27:273-81.

11. Huberty J, Dinkel D, Beets MW, et al. Describing the use of the internet for health, physical activity, and nutrition information in pregnant women. Matern Child Health J 2013;17:1363-72.

12. McManus F, Leung C, Muse K, et al. Understanding 'cyberchondria': an interpretive phenomenological analysis of the purpose, methods and impact of seeking health information online for those with health anxiety. The Cognitive Behaviour Therapist 2015. Available online: https://www.cambridge.org/core/journals/the-cognitivebehaviour-therapist/article/understanding-cyberchondriaan-interpretive-phenomenological-analysis-of-thepurpose-methods-and-impact-of-seeking-healthinformation-online-for-those-with-health-anxiety/9CF314 C9F9DD226A3F4E509541CFAE4D\#fndtn-information

13. Song FW, West JE, Lundy L, et al. Women, pregnancy, and health information online: the making of informed patients and ideal mothers. Gend Soc 2012;26:773-98.

14. Larsson M. A descriptive study of the use of the Internet by women seeking pregnancy-related information. Midwifery 2009;25:14-20.

15. White RW, Horvitz E. Cyberchondria: studies of the escalation of medical concerns in web search. ACM Trans Info Syst 2009;27. Available online: https://www.microsoft. com/en-us/research/publication/cyberchondria-studies-ofthe-escalation-of-medical-concerns-in-web-search/

16. American Psychological Association. The Diagnostic and Statistical Manual of Mental Disorders, Fifth Edition (DSM-5). American Psychological Association 2013.

doi: 10.21037/mhealth.2018.04.04

Cite this article as: Prescott J, Mackie L, Rathbone AL. Predictors of health anxiety during pregnancy. mHealth 2018;4:16.
17. Muse K, McManus F, Leung C, et al. Cyberchondriasis: fact or fiction? A preliminary examination of the relationship between health anxiety and searching for health information on the internet. J Anxiety Disord 2012;26:189-96.

18. Eastin MS, Guinsler NM. Worried and wired: effects of health anxiety in information-seeking and health care utilization behaviors. CyberPsychol Behav 2006;9:494-8.

19. Baumgartner SE, Hartmann T. The role of health anxiety in online health information search. Cyberpsychol Behav Soc Netw 2011;14:613-8.

20. Lagoe C, Atkin D. Health anxiety in the digital age: an exploration of psychological determinants of online health information seeking. Comput Human Behav 2015;52:484-91.

21. Westerneng M, Witteveen AB, Warmelink JC, et al. Pregnancy-specific anxiety and its association with background characteristics and health-related behaviors in a low-risk population. Compr Psychiatry 2017;75:6-13.

22. NHS Choices. (2017). Health anxiety (hypochondria) - Nhs.uk. Retrieved 15 March 2017, Available online: http://www.nhs.uk/conditions/hypochondria/Pages/ Introduction.aspx

23. Owens KM, Asmundson GJ, Hadjistavropoulos T, et al. Attentional bias toward illness threat in individuals with elevated health anxiety. Cognit Ther Res 2004;28:57-66.

24. García-Enguídanos A, Calle ME, Valero J, et al. Risk factors in miscarriage: a review. Eur J Obstet Gynecol Reprod Biol 2002;102:111-9.

25. Savitz DA, Hertz-Picciotto I, Poole C, et al. Epidemiologic measures of the course and outcome of pregnancy. Epidemiol Rev 2002;24:91-101

26. Salkovskis PM, Rimes KA, Warwick HM, et al. The Health Anxiety Inventory: development and validation of scales for the measurement of health anxiety and hypochondriasis. Psychol Med 2002;32:843-53.

27. Rode S, Salkovskis P, Dowd H, et al. Health anxiety levels in chronic pain clinic attenders. J Psychosom Res 2006 60:155-61. 